\title{
Blasting near open pit walls
}

\author{
CK McKenzie Blastechnology, Australia
}

\begin{abstract}
The topic of blasting near pit walls is one that invokes mixed reactions from different mining departments. For many mine operations and mine scheduling departments, it often represents a significant disruption to efficient work flow, while to geotechnical departments it represents a critical component in the task of delivering safe and competent pit walls and compliance with pit slope design.

Many different approaches exist to help achieve the desired end result of safe pit walls and compliance with pit slope design, suggesting that there is no single best-solution. This paper explores some of the contemporary paradigms which strive to achieve the desired end result, with a particular focus on presenting a thought process aimed at trying to avoid unnecessary and ineffective restrictions on mining practices and wall control blasting. Practices such as reduced blasthole diameter, pre-splitting, trim blasting, initiation sequences and systems and reduced blast size will be explored using modelling based upon field measurements. How well do we understand the impacts of blasting on pit wall integrity and pit slope stability?
\end{abstract}

While there is no single design that suits all mining applications, there is a single thought process that should lead each mine to quite quickly decide on the most appropriate solutions for areas of different sensitivity regarding slope stability.

\section{Introduction}

The effect of blasting on slope stability was addressed by Hoek et al. (2002) through the introduction of a blast damage factor, $D$, into the Hoek-Brown failure criterion, and the term is defined and discussed in some detail in Hoek (2012). The blast damage factor has a value between 0 and 1, where 0 represents undamaged rock and 1 represents heavily damaged rock. The term describes, for rock masses of variable geological strength index (GSI), the extent to which the intact rock modulus is degraded to the bulk rock modulus by blast damage. Such a degradation in both modulus and rock strength can occur from either an increased fracture frequency, or by dilation of fractures - both of which can be caused by blasting.

Hoek (2012) presents a series of photographs as a subjective way to estimate the value of the blast damage factor, from which it is concluded that the principal factor affecting the term is the blasthole diameter. Hoek also presents the guidelines below (Figure 1) for estimating the depth, $T$, of the affected zone as a function of bench height, $H$.

- Large production blast, confined and with little or no control

- Production blast with no control but blasting to a free face

- Production blast, confined but with some control, e.g. one or more buffer rows

- Production blast with some control, e.g. one or more buffer rows, and blasting to a free face

- Carefully controlled production blast with a free face

$$
\begin{aligned}
& T=2 \text { to } 2.5 \mathrm{H} \\
& T=1 \text { to } 1.5 \mathrm{H} \\
& T=1 \text { to } 1.2 \mathrm{H} \\
& T=0.5 \text { to } 1 \mathrm{H} \\
& T=0.3 \text { to } 0.5 \mathrm{H}
\end{aligned}
$$

Figure 1 Guidelines for estimating the depth of the blast damage zone (from Hoek 2012)

In summary, it seems clear that Hoek (2012) considered the presence of a free face to play an important role in determining the depth of the blast damage zone (without any mention of the separation distance between the free face and the pit wall), and that the diameter of the production blastholes has a strong impact on the magnitude of the blast damage factor, $D$. 
Open pit blasting must be considered as a mining process with well-defined customers, those being the excavator/truck fleet (pit productivity), the processing plant (plant productivity), and the geotechnical department (pit safety). In addition to these customers there may also be a series of constraints, such as nearby communities, public access ways (environmental impacts) and even company infrastructure such as dewatering bores or industrial structures (asset management).

In today's economic climate, blast design engineers are required to simultaneously satisfy all customers by achieving target pit productivity, target plant throughput, and full compliance with pit slope design. In the case of large-scale mining, this must be achieved with blasthole diameters up to around $400 \mathrm{~mm}$. This paper focuses on the practices commonly adopted in those blasts fired against pit walls, i.e. wall control blasting, and aims to question some of the current design paradigms.

\section{Blast damage mechanisms}

Damage, in the context of this paper, is a change in the rock matrix which will lead to a reduction in the bulk rock strength and bulk rock modulus, includes the creation of new fractures and the dilation of fractures. This definition is considered consistent with Hoek's blast damage factor.

Before attempting to design a blast to mitigate the potentially damaging impacts of blasting on a pit slope, it is useful to understand the mechanisms by which damage might be induced. The principal mechanisms are considered to be:

- Vibration (stress) responsible for creation of fresh fractures.

- Extreme-pressure explosion gases, considered responsible for joint dilation ('confinement').

- The amplitude of reaction forces against the pit wall (release-of-load type of failure).

Some good reference studies of wall control blasting are worth mentioning, including the studies by LeJuge et al. (1994), Ouchterlony (1997), Brent et al. (2001), Spathis et al. (2001), McKenzie and Holley (2004) and McKenzie (2012), which all address, in some detail, the mechanisms of both vibration and gas-related impacts on open pit walls. The topic of release-of-load failure, however, is rarely mentioned in literature and rarely considered in wall control blast design. For greater detail on the principal mechanisms of pit wall damage, readers are directed to the above papers. The remainder of this paper will focus on assessing common wall control blast designs in terms of how they attempt to mitigate against each of the above damage mechanisms.

\section{Common wall control practices}

When deciding on appropriate blast design adjustments for blasts, or rows of blastholes, adjacent to the designed pit wall, blast designers will generally adopt one or more of the following practices - often at the instruction of geotechnical engineers:

- Reduced blasthole diameter.

- Pre-splitting.

- Limited width blasts (e.g. narrow trim blasts).

- Reduced size (rock tonnage) of blasts.

\subsection{Reduced blasthole diameter}

Reducing blasthole diameter has the principal benefit of reducing the radius of high-intensity vibration or dynamic stress, since it can be quite readily shown that the factor having the greatest impact on peak vibration, in the rock mass in close proximity to a column of explosives, is the linear charge load, expressed as the mass of explosive per metre of column length. Figure 2 shows a comparison of the vibration heat 
maps around groups of three blastholes of diameter 102, 150 and $251 \mathrm{~mm}$, assuming the same length and density of explosive, the same rock type and the same powder factor.

$102 \mathrm{~mm}$

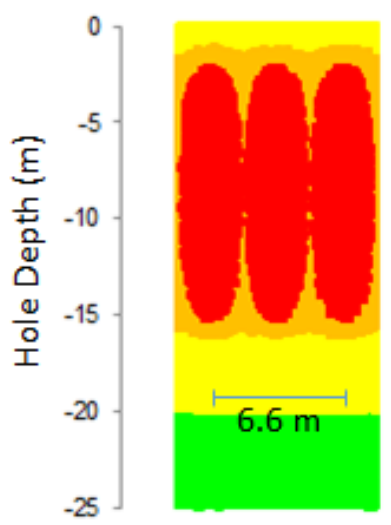

$150 \mathrm{~mm}$

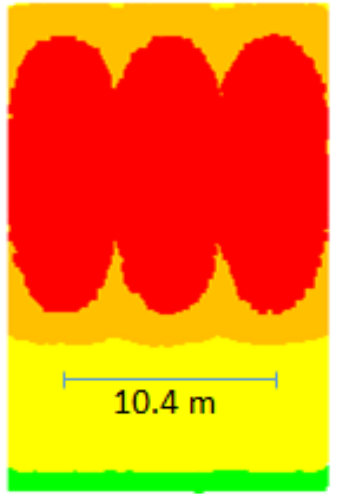

$251 \mathrm{~mm}$

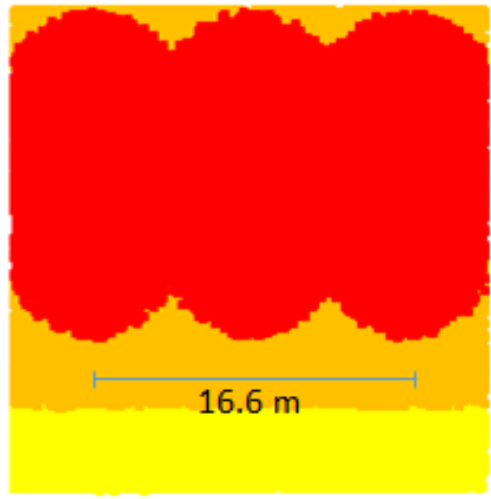

$15000 \mathrm{~mm} / \mathrm{s}$

$10000 \mathrm{~mm} / \mathrm{s}$

$7500 \mathrm{~mm} / \mathrm{s}$

$5000 \mathrm{~mm} / \mathrm{s}$

Figure 2 Heat maps showing vibration intensity around blastholes of 102, 150, and $251 \mathrm{~mm}$ diameter $\left(\mathrm{VOD}=5,000 \mathrm{~m} / \mathrm{s}, \mathrm{V}_{\mathrm{p}}=3,500 \mathrm{~m} / \mathrm{s}, \mathrm{PF}=308 \mathrm{~g} / \mathrm{t}\right.$, primer depth $=14.5 \mathrm{~m}$, hole depth $\left.=15 \mathrm{~m}\right)$

Figure 2 offers quite a compelling case for reducing blasthole diameter in rows of blastholes close to the pit wall, when the main production blasthole diameter is large. The case is much less compelling in small diameter blasting, such as that commonly seen in gold mines and other operations with low bench heights. Attempts to mitigate the vibration impacts of large diameter holes in the back rows of blastholes include the use of low density explosives, decoupled charges (charges of small diameter loaded into large diameter blastholes) and air decks with small base charges.

Figure 3 shows that air decking practices to emulate small diameter holes can be quite successful, offering the mining operator the opportunity to drill all holes with the same diameter and type of drill rig, while reducing total drilled metres. In the case of the air decked holes in Figure 3, the spacing and burden of holes charged with the air decks have been significantly reduced from those used for production blastholes in order to maintain powder factor and fragmentation objectives; however, the patterns are still significantly larger than those which would be obtained using the smaller diameter holes.

$102 \mathrm{~mm}$

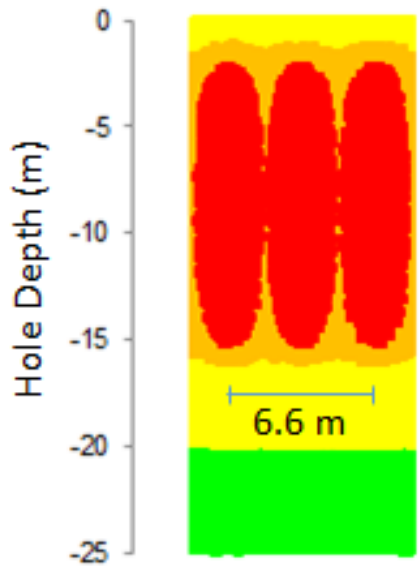

No air deck
$150 \mathrm{~mm}$

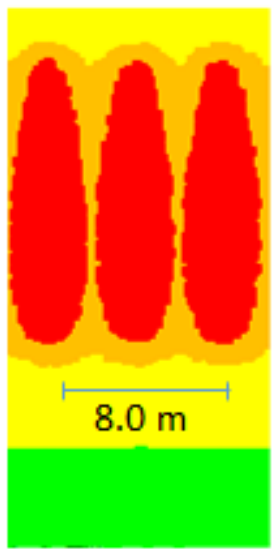

$6 \mathrm{~m}$ air deck
$251 \mathrm{~mm}$

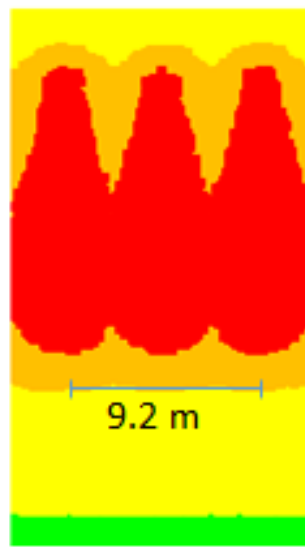

$9 \mathrm{~m}$ air deck

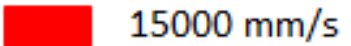

$10000 \mathrm{~mm} / \mathrm{s}$

$7500 \mathrm{~mm} / \mathrm{s}$

$5000 \mathrm{~mm} / \mathrm{s}$

Figure 3 The use of air decks in 150 and $251 \mathrm{~mm}$ diameter blastholes to emulate smaller diameter blastholes in terms of near-field vibration intensities (powder factor constant at $308 \mathrm{~g} / \mathrm{t}$ ) 


\subsection{Pre-splitting}

The theory of pre-splitting as expounded by Calder (1977), Bauer (1982), Chiappetta (1990), and Workman and Calder (1991) revolves around the preferential growth of fractures along a line of light explosive charges fired simultaneously. Ouchterlony (1997) presented the results of a well-controlled and carefully implemented study of pre-splitting in hard rock, showing the importance of precise timing control in achieving the preferential shearing with minimal radial damage to the surrounding rock. With linear charges evenly distributed along the length of the borehole, a well-defined fracture plane can be established in most rock types, provided that the pressure generated in each hole is sufficient to facilitate preferential crack growth between adjacent holes and for the full depth of the bench. If the pressure is insufficient to create preferential crack growth, then the detonation of the charge will produce a random radial crack growth pattern around each hole and the final wall will show little or no evidence of the pre-split blast, other than a discontinuous and occasional series of half barrels. Where the pre-split blast has failed to create a continuous fracture plane over the full length of the pre-split holes, with a high percentage of visible half-barrels, its value to the process of forming clean and stable walls compliant with the designed pit profile must be questioned.

Common pre-splitting practice in modern mining involves the use of hole diameters ranging from 89 to $270 \mathrm{~mm}$, and a maximum pre-split hole spacing in the range 10 to 15 times the hole diameter. Common pre-split explosive diameters range from around 20 up to around $37 \mathrm{~mm}$. Where pre-splitting is practised in large-scale mining, there is a clear trend to use hole diameters of $165 \mathrm{~mm}$ or greater. A pre-split hole spacing of 10 to 15 times the hole diameter, however, can only be achieved if the pre-split charge has been carefully calculated to generate a borehole pressure roughly equal to the compressive strength of the rock. Using the method presented by Calder (1977), Bauer (1982), Chiappetta (1990), and Workman and Calder (1991), this requires that the amount of explosive required to support the above range of hole spacings must increase as rock strength increases. Alternatively, if the mine's practice is to use only a single strand of the continuous pre-split product in each blasthole, then pre-split hole spacing must decrease as rock strength increases.

Considering the common range of explosive product diameters, hole diameters in the range of 89 to $115 \mathrm{~mm}$ can be readily used in rock up to $120 \mathrm{MPa}$, while achieving a hole spacing of 10 to 15 times the hole diameter. For rock with a greater uniaxial compressive strength (UCS), multiple strands of the continuous product will be required - a rare observation in the industry. When only a single strand of the continuous pre-split product is used, larger hole diameters can only support the maximum hole spacing if the UCS of the rock is low (e.g. $50 \mathrm{MPa}$ in the case of $165 \mathrm{~mm}$ diameter holes and $32 \mathrm{~mm}$ diameter pre-split product). It is worth noting that pre-splitting with diameters up to $270 \mathrm{~mm}$ and hole spacing around 3.5 to 4 metres is common in coal strip mining, but those applications generally utilise fully-coupled deck charges with which any desired borehole pressure can be achieved.

The theory of pre-splitting provides little or no guide as to vibration filtering which might be achieved by virtue of any continuous fracture. It is common to read in technical articles emanating from South America that the pre-split acts to filter the vibrations from later-firing production holes, by factors up to $95 \%$ (e.g. Moreno et al. 2008), but more commonly by around 20 to $30 \%$. LeJuge et al. (1994) report no detectable filter effects of the pre-split, despite observing a high percentage of half-barrels in the walls. However, significant reduction is unlikely to be achieved if a continuous fracture is not created due to the mismatch between the borehole pressure and the hole spacing.

\subsection{Trim blasting}

Trim blasting ideally involves the use of very narrow blasts, commonly drilled with a reduced blasthole diameter, and the presence of a clean free-face. Such practices are widely considered to have the least impact on the pit wall, but also usually have a very negative impact on pit productivity and mine scheduling.

The underlying concepts of the trim blast design are considered by the author to be the following:

- Narrow blast ( three rows of blastholes) so as to avoid 'over confinement' of charges adjacent to the pit wall and to avoid dilation of the catchment bench. 
- The use of a clean free-face to permit rapid and unimpeded burden movement and minimise the retention times for the high pressure explosion gases.

- Reduced linear charge concentration near to the pit wall to minimise levels of vibration induced in the wall adjacent to the trim blast.

- Initiation sequence to promote movement of rock in a direction almost perpendicular to the wall so as to avoid 'over confinement' in the rear rows of blastholes adjacent to the pit wall.

While the above concepts seem appropriate, the reality of trim blasting as practised in many large open pit mines is somewhat different and can be summarised as below:

- Narrow blasts are unusual, and trim blasts will commonly have five rows of blastholes, or more.

- Clean free-faces are unusual as they have a negative effect on excavator productivity.

- Preferred use of a single blasthole diameter.

- Confinement of charges near to the pit wall often greater than in the production blast due to reduced powder factors, increased stemming lengths and the common use of air-decks in buffer holes.

Given that actual trim blasting practices commonly differ markedly from the ideal practices designed to minimise all damage mechanisms, the persistence of the use of the method demands scrutiny, and the method itself may not always produce the expected results in terms of bench stability.

\subsection{Limiting blast size}

In some stability-sensitive areas of large open pits, it is not uncommon to find that blast size is restricted as a means of limiting the impact of the blast on the pit wall. Importantly, such restrictions can have a major impact on scheduling and excavator productivity. Where such restrictions are imposed, it is understood that the concept is to limit the length of the pit wall that will be subjected to relaxation as the buttress is suddenly removed from the toe of the slope. However, a long and low tonnage trim blast will expose the same length of pit wall as a large tonnage blast of the same length containing many more rows of blastholes than the trim blast.

Vibration modelling (Figure 4) shows that there is no significant difference to the pit wall between a trim blast with two buffer rows and two production rows, and a large blast with the same two buffer rows and eight production rows. The modelling is supported by field work reported by Blair and Armstrong (2001) and McKenzie (2012) that both report vibration levels to be independent of burden and confinement. Over the range of pit wall depths considered by Hoek (2012) to apply to the blast damage factor (i.e. 0-2.5 times the bench height), vibration impacts are typically controlled by the three to five rows closest to the wall when the blasts involve buffer holes with reduced charges, and to one or two rows when buffer rows are absent.

2 rows production holes, 2 rows buffer holes

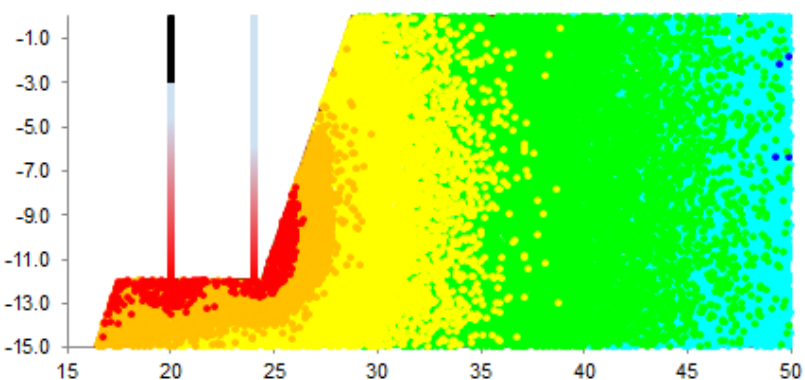

8 rows production holes, 2 rows buffer holes

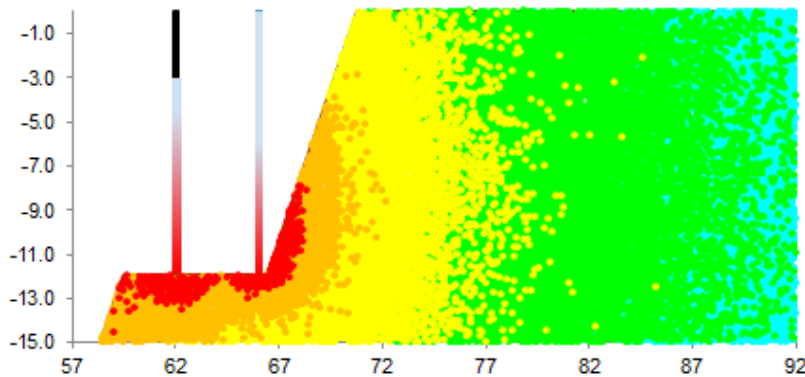

Figure 4 Increasing the number of blasthole rows has no significant impact on the vibration/stress regime induced in the pit wall 


\section{$4 \quad$ Vibration-induced damage and its mitigation}

Numerous studies have been conducted into the effect of high vibration levels on rock damage (Holmberg \& Persson 1979; Ouchterlony 1993; LeJuge et al. 1994; McKenzie et al. 1995; Ouchterlony et al. 1996; Brent et al. 2001; McKenzie \& Holley 2004), with useful correlations proposed between peak vibration levels and the extent of damage. Furthermore, a critical vibration level and its relationship to UCS is defined for the initiation of fresh fracturing, as well as levels at which dilation and over-break could reasonably be expected. In summary, the critical vibration level, $\mathrm{PPV}_{c}$, at which fresh fracturing can be expected is given by (McKenzie et al. 1995):

$$
P P V_{c}=\frac{\sigma_{T} \times V_{p}}{E} \approx \frac{1.25 \times \sigma_{T}}{V_{p} \times \rho_{\text {rock }}}
$$

where:

$$
\begin{aligned}
& \sigma_{T}=\text { intact tensile strength of the rock (MPa). } \\
& V_{\mathrm{p}}=\text { p-wave velocity of the intact rock }(\mathrm{m} / \mathrm{s}) . \\
& E \quad=\text { intact Young's Modulus (MPa). } \\
& \rho_{\text {rock }}=\text { density of an intact rock specimen }\left(\mathrm{kg} / \mathrm{m}^{3}\right) .
\end{aligned}
$$

The critical particle velocity term, $\mathrm{PPV}_{c}$, will have the units of $\mathrm{m} / \mathrm{s}$. Over-break can be expected to occur at levels between four and eight times $\mathrm{PPV}_{c}$, and vibration-induced dilation at levels as low as about $P P V_{c} / 4$, though dilation will be affected by confining stresses, e.g. an overlying bench in the case of a double batter.

Blair and Armstrong (2001) and McKenzie and Holley (2004) report no difference in peak vibration levels measured behind trim and production blasts. Brent et al. (2001) report no influence of burden dimension (confinement) on peak vibration levels. These observations lead to the obvious conclusion that narrow blasts are unlikely to have any benefit in terms of vibration reduction, irrespective of the presence or otherwise of a free face. Vibration levels in close proximity to a blast are controlled by the linear charge load (kilograms of explosive per metre of blasthole), and are not significantly influenced by confinement or the presence of a free face.

Vibration control should therefore focus on the linear charge load in the back few rows of blastholes and, in the special case of a charge with an air deck, the charge load should be considered to be distributed over the length of the charge deck plus the air deck. If vibration monitoring is to be conducted for the purposes of assessing impact on pit walls, it will be necessary to either extrapolate levels from measurements made at a safe distance from the blasts or to directly measure levels behind blasts, which will require specialised monitoring equipment and the use of accelerometers.

\section{$5 \quad$ Gas pressure-induced damage and its mitigation}

Studies by LeJuge et al. (1994), Ouchterlony et al. (1996), Brent et al. (2001), McKenzie and Holley (2004) and Green (2015) all demonstrate very clearly the dilation which normally occurs behind blasts, often extending the entire width of the catchment berm. Ouchterlony et al. (1996) report dilation occurring up to 20-25 metres behind blasts with $311 \mathrm{~mm}$ diameter holes and 15 metre benches. Sometimes the dilation is accompanied by high pressure gas ingress, and sometimes it is not. It is also generally reported that pre-splits, if effectively created, act to terminate gas flows, but do not terminate bench dilation.

Importantly, Ouchterlony et al. (1996) concluded that with un-stemmed blastholes adjacent to the pit wall, high pressure gas ingress does not occur or contribute significantly to wall damage, whereas LeJuge et al. (1994) showed very significant gas ingress behind stemmed blastholes. Green (2015) presents compelling photographic evidence that the absence of stemming, in conjunction with reduced buffer row charges, is an extremely effective way of controlling bench dilation. The photographs in Figures 5 and 6 are those presented by Green (2015). 

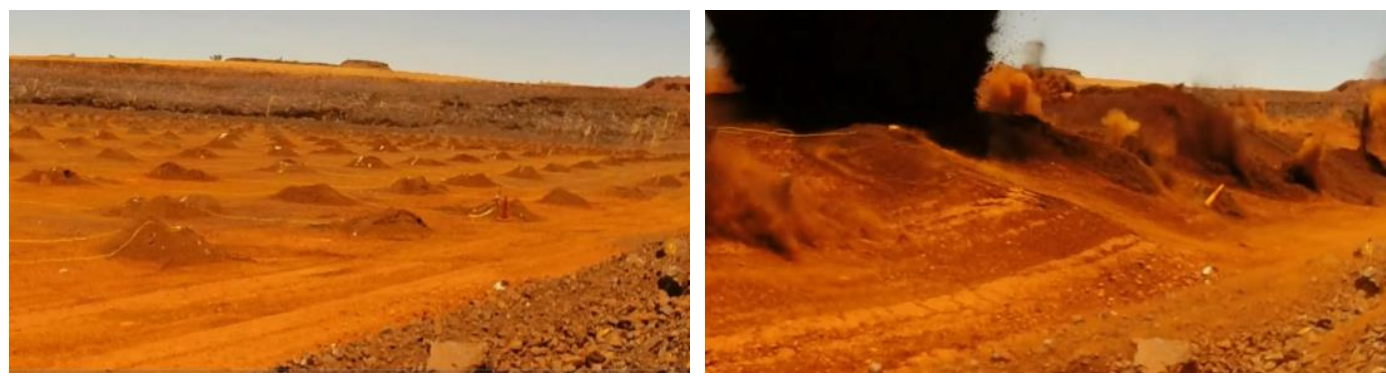

Figure 5 Dilation occurring behind stemmed blastholes (12 $\mathrm{m}$ bench, $251 \mathrm{~mm}$ diameter)
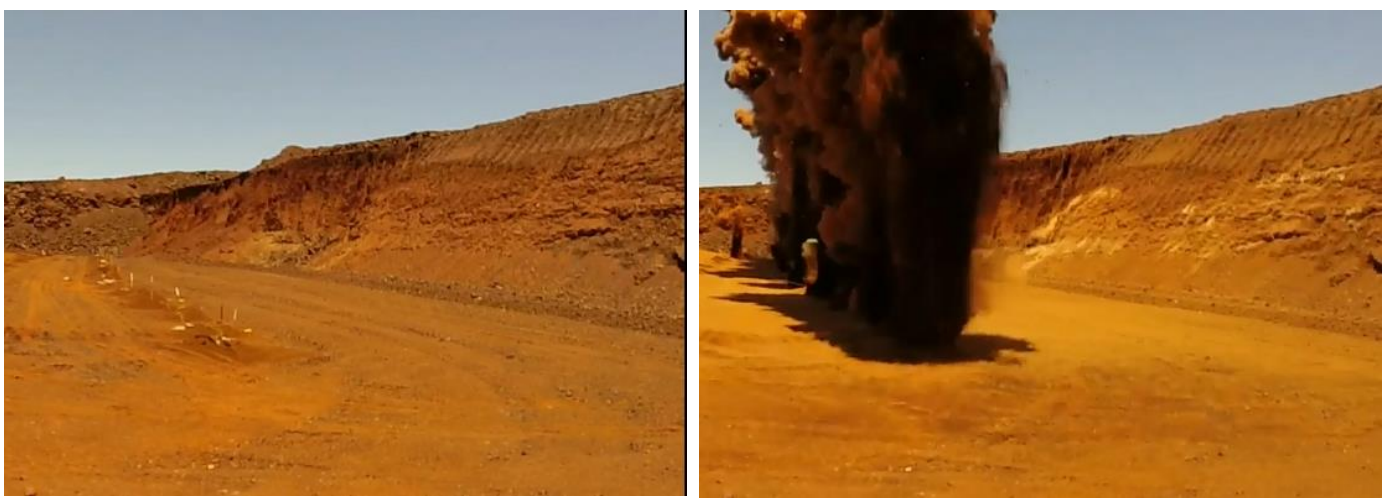

Figure 6 Absence of dilation in bench behind un-stemmed buffer blastholes (12 m bench, $251 \mathrm{~mm}$ diameter)

In the author's own recent experience using the close-in photography adopted by Green (2015), it is clear that even very short stemming columns produce significant dilation around blastholes. An effective mitigation method is therefore considered to be the complete removal of stemming from at least the back row of blastholes, and possibly from the last two rows of blastholes. While the absence of stemming results in an increase in overpressure levels (particularly the audible frequencies), it is observed that flyrock ejected from the holes has an almost vertical trajectory and its maximum projection distance does not seem to exceed 200 metres.

\section{Release-of-load induced damage and its mitigation}

The release-of-load failure mechanism referred to in this paper is not that which occurs by removal of the buttress at the toe of the slope, but rather the response of the wall to the heaving of the muckpile by the high-pressure explosion gases. Where the direction of displacement of the muckpile occurs perpendicular to the pit wall, an equal and opposite reaction force will be exerted into the pit wall (Figure 7).

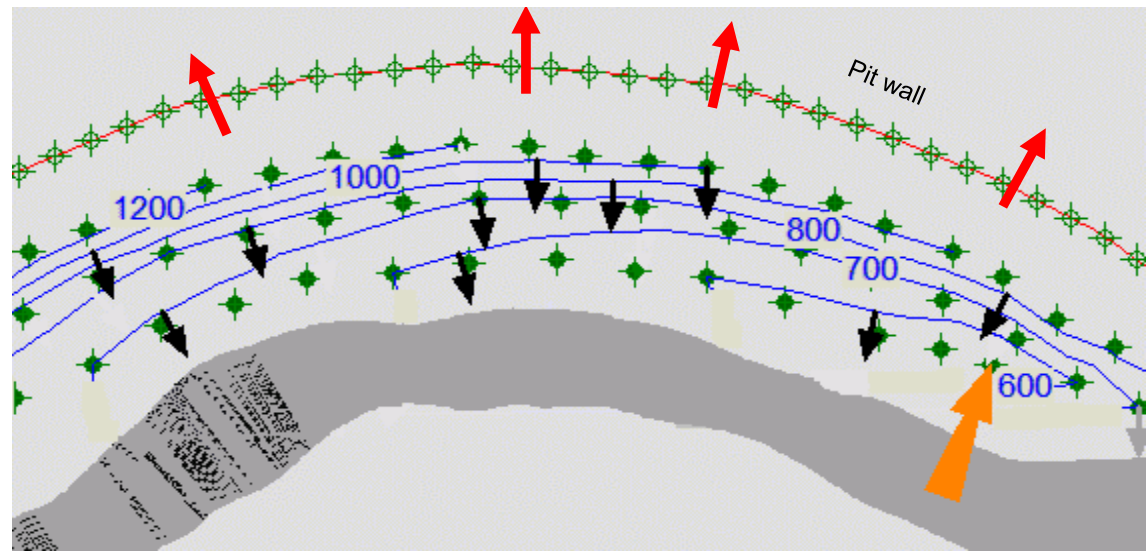

Figure 7 Typical initiation timing and muckpile displacement for narrow blast patterns. Black arrows indicate direction of material movement, red arrows indicate reaction forces (after McKenzie 2012) 
Once muckpile displacement occurs, relaxation of the pit wall follows, leading to tensile cracking parallel to the pit wall. In the case of structures which dip into the pit, the reaction forces can alternatively lead to displacement of wedges along joint planes, as exemplified in the photograph of Figure 8. Clearly, the longer the time over which the high explosion gas pressures are able to act, the greater is the potential for both wedge displacement and tensile failure.

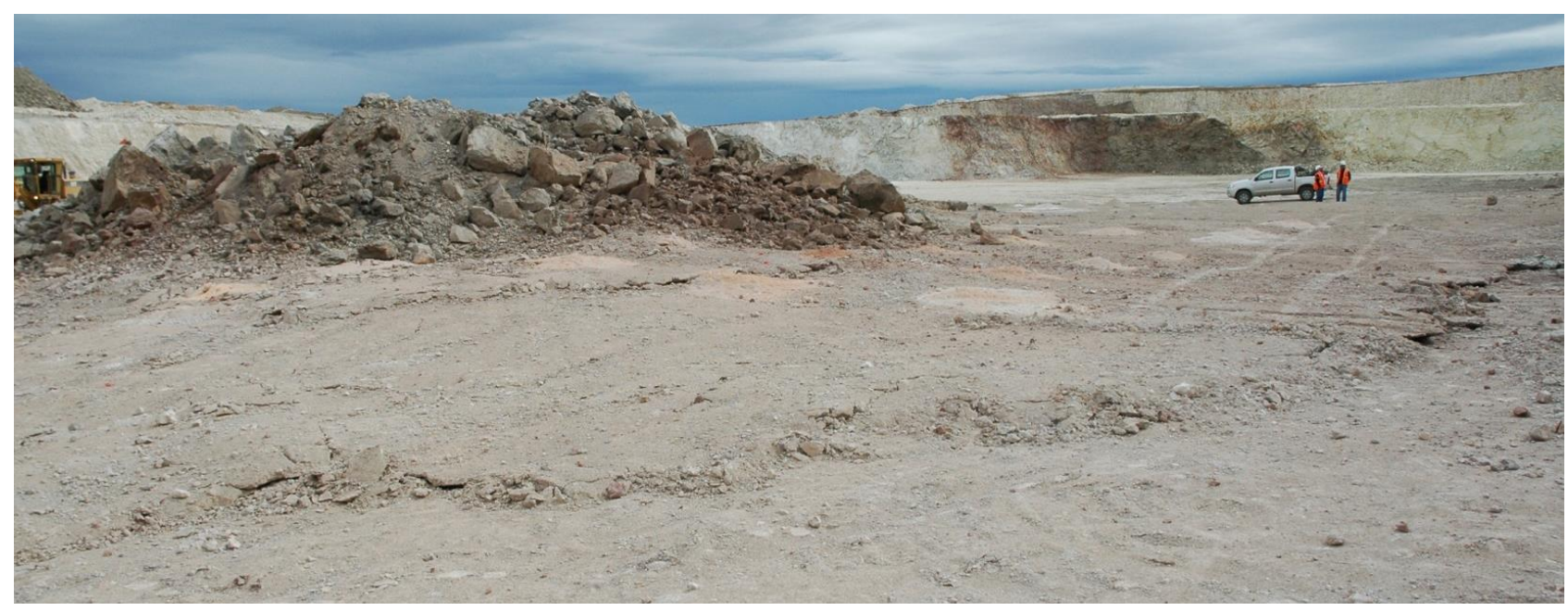

Figure 8 Displacement of wedge occurring along joint planes and extending more than 10 metres behind a production blast with $127 \mathrm{~mm}$ diameter blastholes

Mitigation methods would include a change to the initiation sequence so that bulk rock movement does not occur perpendicular to the pit wall, and also the use of small, un-stemmed buffer row charges in the last two rows of blastholes.

\section{Quantitative estimates of the blast damage factor}

Given what is now known about vibration levels, rock mass dilation, and gas penetration into dilated joints, it is worth revisiting the blast damage factor to see if its value can be calculated in a more objective manner than that presented by Hoek (2012). In summary:

- A critical vibration level can be estimated as a function of intact rock strength.

- Vibration levels can be estimated using either basic attenuation equations or advanced modelling, which takes into consideration delay timing, initiation system, and explosive properties in large blasts.

- Vibration levels do not increase as a result of confinement and are not affected significantly by either the presence or the absence of a free face.

- Large diameter blastholes can go a long way towards emulating the vibration impacts from small diameter holes if the charges are small (requires reduced spacing and burden).

- Dilation can extend behind a blast pattern to a distance of around 1.2 times the bench height, though the distance will depend strongly on vertical confining stresses such as an overlying catchment berm (e.g. in the case of a double batter).

- Dilation occurs even with very short stemming columns, but almost disappears for un-stemmed blastholes with short charges relative to the bench height.

- Pre-splitting does not terminate dilation of the catchment berm.

- High pressure gases do not penetrate into the pit wall if the charges are not stemmed. 
- Initiation sequences are easily modified to ensure that reaction forces do not act perpendicular to the pit wall, and the tendencies for release-of-load failure and wedge displacement are reduced.

The previous observations and conclusions from a wide range of field studies in a wide range of rock types suggests that the blast damage factor can probably be quite well estimated from vibration modelling, provided that the factors of dilation and initiation sequence are appropriately controlled.

Equation (1) presents a method to estimate the critical vibration level $\left(P P V_{c}\right)$ at which fresh fracturing of intact blocks will commence, and seems like an appropriate definition of the limit for the disturbed zone, assuming that appropriate controls have been initiated to eliminate dilation. Modelling has used a PPV value of $750 \mathrm{~mm} / \mathrm{s}$, consistent with the following mechanical rock properties:

- Uniaxial compressive strength: $70 \mathrm{Mpa}$.

- Intact Young's Modulus: $30 \mathrm{GPa}$.

- Rock density: $2,650 \mathrm{~kg} / \mathrm{m}^{3}$.

- Compressional wave velocity: 3,800 m/s.

Modelling takes into consideration burden and spacing dimensions, individual hole charging configurations, delay timing, initiation timing and system, explosive VOD, compressional wave velocity, point of initiation within the explosive columns and the site-dependent vibration attenuation properties of the rock mass. It allows quantitative assessment of the thickness of the damage zone, with the limit of damage being defined in terms of the critical PPV.

Figure 9 provides some insights into Hoek's (2012) table for rating the blast damage factor for blasts with and without adjustments to the rows of holes adjacent to the pit wall. In all cases, all production holes were modelled with a diameter of $251 \mathrm{~mm}$, a $1.2 \mathrm{~g} / \mathrm{cc}$ Heavy ANFO product of VOD 5,000 m/s, and bottom-of-hole initiation with non-electric detonators.

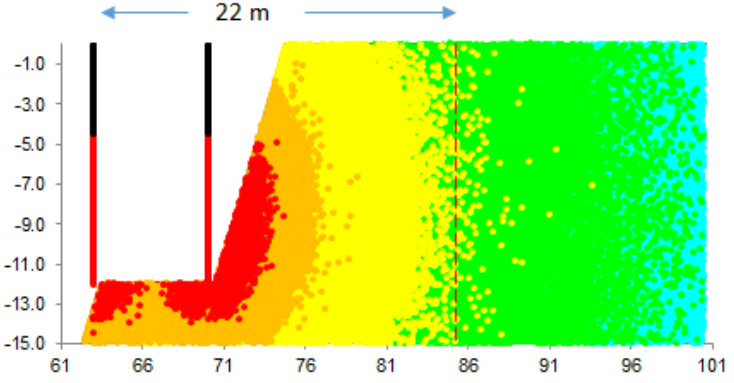

(a) No Buffer rows, $251 \mathrm{~mm}$

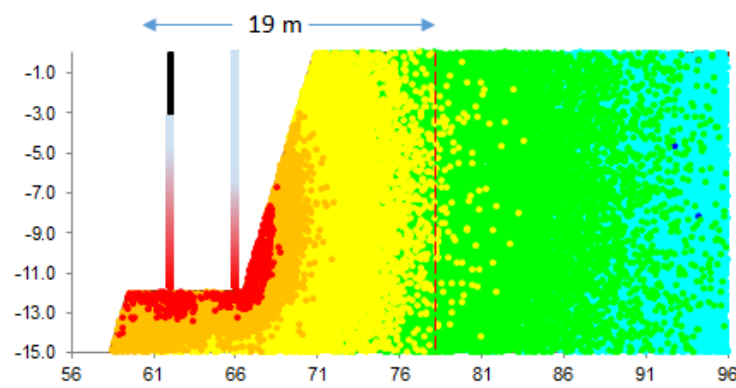

(c) $2 \times 251 \mathrm{~mm}$ Buffer Rows

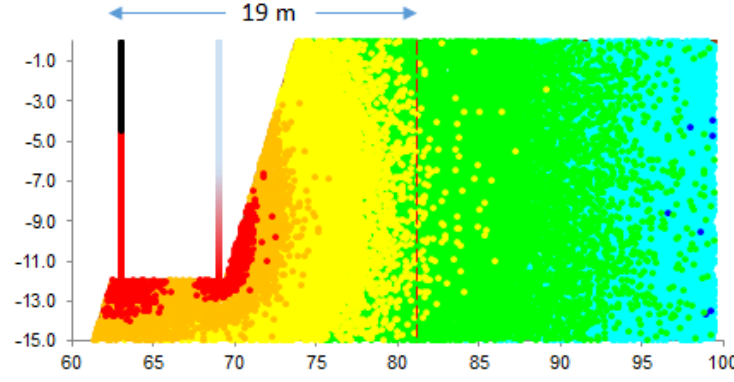

(b) $1 \times 251 \mathrm{~mm}$ Buffer Row

$2500 \mathrm{~mm} / \mathrm{s}$

$1000 \mathrm{~mm} / \mathrm{s}$

$500 \mathrm{~mm} / \mathrm{s}$

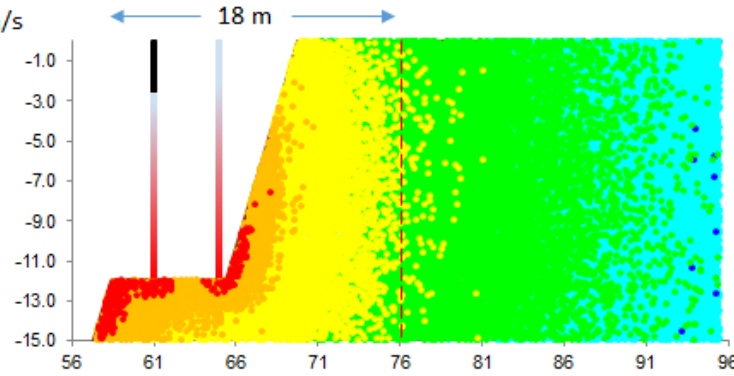

(d) $2 \times 165$ mm Buffer Rows

Figure 9 Quantitative assessment of the Blast Damage Zone using vibration heat map modelling. Dashed vertical lines represent the point in the rock mass where the vibration level averages $750 \mathrm{~mm} / \mathrm{s}$ 
Without any controls, blast damage from the $251 \mathrm{~mm}$ diameter blastholes can be seen to extend approximately 22 metres into the pit wall, corresponding to a factor of 1.8 times the bench height (12 metres). The use of a single row of buffer holes with reduced charging reduces this damage zone by three metres. Only slight further reduction is achieved by using two buffer rows of $165 \mathrm{~mm}$, so that the width of the blast damage zone reduces from 1.8 times the bench height to 1.5 times the bench height as a result of incorporating two smaller diameter buffer rows. The biggest impact of the buffer rows is in reducing the zone of intense damage (i.e. the red zone) in the toe region of the bench, from which it must be concluded that while buffer rows reduce the intensity of damage visible in bench faces after blasting, their effect on the width of the blast damage zone may be quite small. Note that neither monitoring nor modelling indicates that the presence of a free face will have any impact on peak vibration levels.

Further modelling has investigated the difference between large diameter $(251 \mathrm{~mm})$ blasting and intermediate diameter $(165 \mathrm{~mm})$ blasting, as presented in Figure 10.

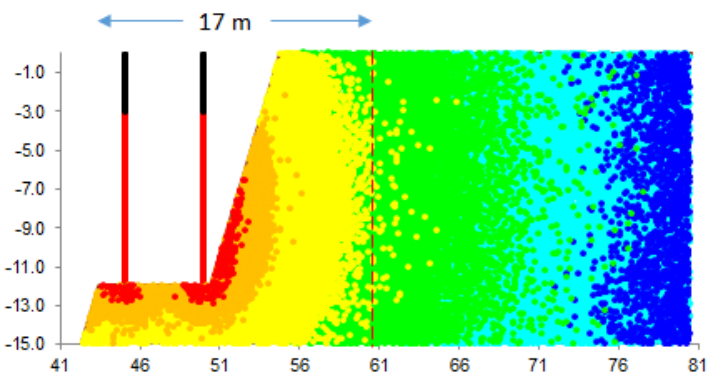

All rows $165 \mathrm{~mm}$, no buffer

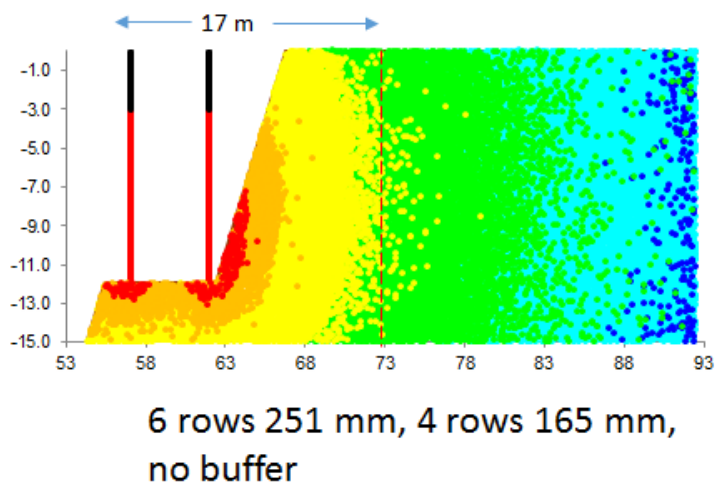

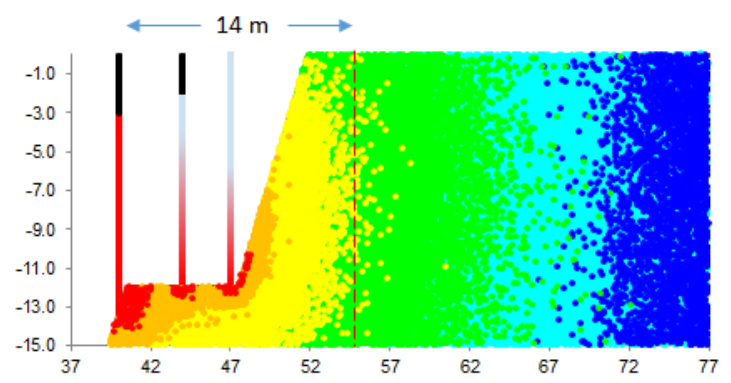

All rows $165 \mathrm{~mm}, 2$ rows buffer $1000 \mathrm{~mm} / \mathrm{s}$ $500 \mathrm{~mm} / \mathrm{s}$ $250 \mathrm{~mm} / \mathrm{s}$

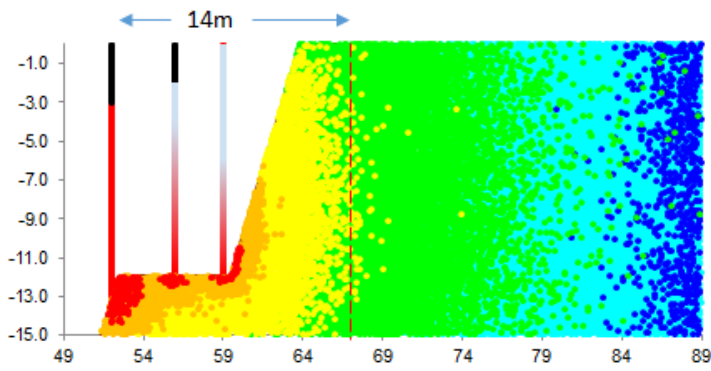

6 rows $251 \mathrm{~mm}, 2$ rows $165 \mathrm{~mm}$, 2 rows $165 \mathrm{~mm}$ buffer

Figure 10 Blast damage zone from smaller diameter blastholes (same simulation conditions as for Figure 9 and same powder factor)

A comparison between Figures 9 and 10 reveals that a smaller hole diameter does reduce the width of the damage zone, even if there are no buffer holes adjacent to the wall (from 1.8 times the bench height to 1.4 times the bench height). The width of the damage zone can approach the bench height if buffer charges are used in the two rows nearest to the wall, and after some critical distance from the wall, production blasting with the larger diameter holes can proceed. The critical distance will depend on the two different hole diameters being used, but it is clear that it is likely to involve more than two rows of reduced diameter, or two rows of reduced charges, to minimise the width of the damage zone.

The width of the damage zone will also depend, of course, on the rock strength. For rock with a significantly lower $\mathrm{PPV}_{c}$, the width of the damage zone will probably be significantly greater than it is for a rock with a high PPV . Holmberg and Persson (1979) report a critical particle velocity of around 1,000 mm/s in Swedish granite, and McKenzie et al. (1995) estimate levels as low as $350 \mathrm{~mm} / \mathrm{s}$ for some sedimentary rocks. It must also be remembered, though, that the weaker rock types are also likely to have higher vibration attenuation rates, so that the width of the damage zone really requires rock-specific modelling. 
The modelling suggests that Hoek's (2012) guidelines may be a little conservative, but probably should be adjusted to include the influence of rock strength and probably should be reviewed in regards to the role of the free face. The width of the blast damage zone seems to be reasonably well supported by modelling, which offers the advantage of quantitative assessment in site-specific conditions.

\section{Conclusion}

The blast damage factor as currently used by many geotechncial engineering groups can probably be estimated using modelling, offering the advantage of objective and site-specific assessment.

Based on site work, advanced modelling, and supported by literature reviews, a number of critical factors have recently emerged which are somewhat at odds with conventional thinking and conventional wall control blast practice. When carefully implemented they offer significant opportunities for improved pit productivity and working efficiency, and offer a paradigm shift in terms of how wall control blasting can be implemented.

1. The presence of a free face provides no significant benefit in terms of vibration reduction in the pit walls.

2. The best way to address confinement issues (commonly considered the role of the free face) is to remove the stemming from the one or two rows of blastholes drilled closest to the pit wall.

3. The charging of large diameter blastholes can be adjusted to very significantly reduce the extent of intense damage around the toes of the catchment benches. This has allowed many operations to design wall control blasts with all holes drilled at the same diameter as the production holes.

4. The width of the blast damage zone, defined using the critical PPV for the rock mass, is controlled by the charge configurations in the back rows of wall blasts - probably involving at least the four rows closest to the wall. Common practice is to use only one or two rows of holes featuring reduced charging as Buffer rows.

5. Since both vibration and gas pressure influences are, or can be made to be, independent of factors such as free faces and blast size, effective wall control blasting can be undertaken without any constraints on blast width or size. This offers very significant opportunities to mine planning and equipment scheduling, without negative impact on wall damage.

6. Careful initiation design ensures that pressure applied to the pit wall by the explosion gases is directed so as to minimise release of load failure and wedge displacement in catchment benches.

7. Pre-splitting does not terminate bench dilation from adjacent stemmed blastholes, and generates its own dilation effects extending into the catchment bench area.

8. For pre-split blasting to be effective, hole charging and hole spacing must be matched to the rock strength. The pre-split may or may not provide additional vibration attenuation.

\section{References}

Bauer, A 1982, 'Wall Control Blasting in Open Pits', in Proceedings of the 14th Canadian Rock Mechanics Symposium, pp. 3-10.

Blair, DP \& Armstrong, LW 2001, 'The influence of burden on blast vibration', Fragblast - International Journal for Blasting and Fragmentation, Balkema, Rotterdam.

Brent, GF, Smith, GE \& Lye, GN 2001, 'Studies on the Effect of Burden on Blast Damage and the Implementation of New Blasting Practices to Improve Productivity at KCGM's Fimiston Mine', in Explo 2001 Proceedings, AusIMM.

Calder, P 1977, 'Pit Slope Manual, Chapter 7 - Perimeter Blasting', CANMET Report 77-14, Canadian Center for Mineral and Energy Technology.

Chiappetta, F 1990, 'Pre-splitting and controlled blasting techniques', in Proceedings of the 2nd High Tech Seminar, ISEE, Cleveland.

Green, B 2015, 'Megablasts - Enabling technologies in BHP Billiton Iron Ore', in Proceedings of the International Symposium on Rock Fragmentation by Blasting, pp. 599-606.

Hoek, E 2012, 'Blast Damage Factor, D', Technical note for Rocscience, 2 February 2012.

Hoek, E, Carranza-Torres, CT \& Corkum, B 2002, 'Hoek-Brown failure criterion-2002 edition', in Proceedings of the Fifth North American Rock Mechanics Symposium, Toronto, vol. 1, pp. 267-273. 
Holmberg, R \& Persson, P-A 1979, 'Design of tunnel perimeter blasthole patterns to prevent rock damage', Tunnelling '79: Proceedings of the Second International Symposium, IMM, London, pp. 280-283.

LeJuge, GE, Jubber, L, Sandy, DA \& McKenzie, CK 1994, 'Blast Damage Mechanisms In Open Cut Mining', Open Pit Blasting Workshop 94, AusIMM.

McKenzie, CK 2012, 'Limits Blast Design: Controlling Vibration, Gas Pressure \& Fragmentation', in Singh \& Sinha (eds), Proceedings of the 10th International Symposium on Rock Fragmentation by Blasting, New Delhi.

McKenzie, CK \& Holley, K 2004, 'A study of damage profiles behind blasts', in Proceedings of the 30th Annual Conference on Explosives and Blasting Techniques, International Society of Explosives Engineers, vol. 2.

McKenzie, CK, Scherpenisse, CR, Arriagada, J \& Jones, J 1995, 'Application of computer assisted modelling to final wall blast design', in Explo '95 Proceedings, AusIMM , pp. 285-292.

Moreno, E, Sanhueza, JC \& Vanbrabant, F 2008, 'Balance fragmentación-daño en zona primaria en Mina Los Pelambres, ASIEX', VI Jornadas de Tronadura, Pucón, Chile. [in Spanish]

Ouchterlony, F 1993, 'Blast damage predictions from vibration measurements at the SKB underground laboratories at Äspö in Sweden', in Proceedings of the 19th Annual Conference on Explosives and Blasting Techniques, International Society of Explosives Engineers, vol. 2.

Ouchterlony, F 1997, 'Prediction of crack lengths in rock after cautious blasting with zero inter-hole delay', International Journal for Blasting and Fragmentation, vol. 1, pp. 417-444.

Ouchterlony, F, Nie, S, Nyberg, U \& Deng, J 1996, 'Monitoring of large open cut rounds by VOD, PPV and gas pressure measurements', in B Mohanty (ed.), Proceedings of the 5th International Symposium on Rock Fragmentation by Blasting, Balkema, Rotterdam, pp. 167-176.

Spathis, AT, Smith, GE, Yacob, I \& Labriola, A 2001, 'Wall Control at the Freeport Grasberg Opencut Mine: Vibration and Gas Penetration Measurements as a Precursor to Improvements', in Proceedings of the 27th Annual Conference on Explosives and Blasting Techniques, International Society of Explosives Engineers, vol. 2.

Workman, JL \& Calder, PN 1991, 'A method for calculating the weight of charge to use in large hole pre-splitting for cast blasting operations', in Proceedings of the 17th Annual Conference on Explosives and Blasting Techniques, International Society of Explosives Engineers, vol. 2. 